\title{
EL LEGADO DE LA REAL EXPEDICIÓN FILANTRÓPICA DE LA VACUNA (1803-1810): LAS JUNTAS DE VACUNA
}

\section{Susana María Ramírez Martín}

Dra. Historia de América

\section{RESUMEN}

La Expedición de la Vacuna, dirigida por los médicos Francisco Xavier Balmis y José Salvany, es la gesta científica y sanitaria más importante de época colonial. Su desarrollo tuvo lugar en un momento político convulso y los resultados estuvieron condicionados por las sociedades donde la vacuna se estableció. El legado de esta expedición filantrópica fue la creación de las Juntas de Vacuna. Estas instituciones se erigieron como centros creadores de saber médico en América y consolidaron el objetivo primario de la expedición: la búsqueda de la salud pública luchando contra las epidemias de viruela.

PALABRAS CLAVE: Fracisco Xavier Balmis, José Salvany, vacuna, viruela, juntas de vacuna, América.

\section{SUMMARY}

The Royal Vaccination Expedition, directed by the physicians Francisco Xavier Balmis and José Salvany, was the most important scientific and medical achievement of the Spanish colonial era. It took place at a time of political restlessness, and its achievements were thus conditioned by each of the cultures into which the vaccine was introduced. As its legacy, the philantropic expedition left the Vaccination Boards, established in the Americas as centers of medical expertise to sustain the expedition's principal objetive: the battle against the smallpox epidemics in pursuit of public health.

KEY WORDS: Francisco Xavier Balmis, José Salvany, vaccine, smallpox, vaccination boards, America

En 1803 se inicia una de las gestas médicas más importantes de la historia de medicina española durante el período colonial: La Real Expedición Filantrópica 
de la Vacuna (1803-1810) ${ }^{1}$. Esta vuelta al mundo que propaga la salud se enmarca dentro del conjunto de las expediciones ilustradas realizadas por España en los territorios americanos a lo largo del siglo XVIII. Mi estudio va a centrarse en el legado dejado a modo de sementera en favor de la sanidad pública.

\section{GÉNESIS DE UNA EXPEDICIÓN}

Desde que se estableció en España en 1700, la monarquía borbónica había padecido reiteradamente el azote de las viruelas. Las epidemias no tenían en cuenta rango, posición, sexo, estado.... Afectaban tanto a los territorios metropolitanos como ultramarinos. Durante las epidemias de viruelas en los siglos XVI y XVII, las poblaciones americanas quedaban diezmadas de un 20 a un 50\% dependiendo de la composición étnica de los asentamientos. La mortalidad era mayor en los poblados indígenas que en las ciudades que tenían una mayoría hispana. En junio de 1802, se desencadenó en el Virreinato de Nueva Granada una epidemia de grandes proporciones. El miedo se adueñó de los pobladores. Las súplicas de los gobernadores locales llegaron a los oídos del monarca en la Navidad de 1802. La situación que describen los documentos es aterradora ${ }^{2}$. El Rey decide pasar una consulta a su Consejo en enero de 1803. Se actúa con rapidez. En marzo de 1803, se declara que es conveniente la difusión de la vacuna contra la viruela para frenar la epidemia

1 Esta Expedición ha sido estudiada profundamente en contadas ocasiones. Presento en esta nota las referencias bibliográficas de apoyo para la profundización sobre el tema. Solamente citaré las revisiones y estudios realizados en los últimos cinco años. BALAGUER PERIGÜEl, E. y BALlester AÑon, R. (2003), En el nombre de los niños: La Real Expedición Filantrópica de la Vacuna (1803-1806), Asociación Española de Pediatría, s/1; DÍAZ DE YraOla, G. (2003), La vuelta al mundo de la Expedición de la Vacuna (1803-1810), Facsímil de la edición de 1948 y versión inglesa traducida y editada por Catherine Mark, CSIC, Madrid; RAMírez Martín, S. (1999), La mayor hazaña médica de la Colonia. La Real Expedición Filantrópica de la Vacuna en la Real Audiencia de Quito, Ed. Abya-Yala, Quito; RAMíREZ MARTín, S. (2002), La salud del Imperio. La Real Expedición Filantrópica de la Vacuna, Ed. Doce Calles, Madrid; Tuells, J. y Ramírez, S. (2003), Balmis et Variola, Consejería de Sanitat de la Generalitat Valenciana, Valencia.

2 Las noticias sobre la gran epidemia de viruelas, «con la imposibilidad de aislar a los virolentos en el único hospital que existía en la Capital del Virreinato de Nueva Granada», llegan a la Península en un Informe del Virrey en el que comunica las medidas de urgencia tomadas ante la tragedia. Informe del Virrey de Nueva Granada, fechado en Caracas el 12 de junio de 1802. Expediente 1. Extracto General de la Expedición Filantrópica de la Vacuna. Archivo General de Indias [AGI] Indiferente General [IG] 1558-A. 
en el territorio neogranadino para evitar que la epidemia se propague por América Meridional. El Consejo de Indias propone la expedición como modo de propagar la vacuna en los territorios ultramarinos.

En la primavera de 1803 todos los preparativos para una posible expedición están vistos y analizados por la vía de urgencia. El dramatismo de las noticias exige reacciones y respuestas rápidas. La velocidad de tramitación de la burocracia estatal fue inusual. Solamente transcurrieron ocho meses desde que la empresa se ideó (28 de marzo de 1803), hasta que se inició (30 de noviembre de 1803). Esta inmediatez manifiesta la urgencia del proyecto sanitario. Una vez decidida la actividad, el problema radica en la financiación y en la legislación que permita desarrollar el proyecto expedicionario.

Todos los gastos de la navegación y transporte de los expedicionarios corrían a cargo de la Real Hacienda. De este modo el poder público hispano controlaba la principal hazaña sanitaria del mundo ilustrado. Una vez llegados los expedicionarios a territorio americano, pasaban a depender de las autoridades ultramarinas, que podían financiar los gastos de los expedicionarios desde el Ramo de Tributos de los Indios, los Censos de Indios, el Ramo de Propios o los Diezmos Eclesiásticos. Saliese de donde fuese el dinero para sostener la Expedición, los documentos matizan: «baxo condiciones equitativas y ventajosas para la hacienda ${ }^{3}$.

Por otro lado, la expedición no se dejó al arbitrio de la fortuna. Está regulado todo. Desde el inicio, el director de la expedición demanda y la Corona emite legislación que normalice toda la actuación de la Real Expedición. La legislación establece unos protocolos de actuación de cada uno de los miembros y del grupo que garantizarán el éxito. El proyecto profiláctico estaba perfectamente definido en la teoría. Los documentos creaban una idea que había que llevar a la práctica. Hacen falta brazos. Gente que se comprometa con el proyecto y que lo consiga con éxito. Fueron los siguientes. Como director: Francisco Xavier Balmis y Berenguer. Como ayudantes: José Salvany y Lleopart (que durante la expedición sería nombrado subdirector), Manuel Julián Grajales y Antonio Gutiérrez Robredo. Como practicantes: Francisco Pastor Balmis y Rafael Lozano Pérez. Como enfermeros: Basilio Bolaños, Pedro Ortega y Antonio Pastor. Como cuidadora de los niños, Balmis elige a la Rectora de la Casa de Expósitos de La Coruña: Isabel Sendales y Gómez. Como transmisores de salud, un grupo incalculable de niños que sirvieron

3 Real Orden fechada el 30 de agosto de 1803. Expediente 3, Extracto General de la Expedición Filantrópica de la Vacuna. AGI: IG, 1558-A. 
para transportar la vacuna por todo el mundo, y que permitieron que la cadena profiláctica de brazo a brazo no se rompiera.

Los cargos de los expedicionarios estaban perfectamente diferenciados. Cada miembro tenía unas funciones, obligaciones y responsabilidades propias, con el fin de no solapar esfuerzos ni dejar vacíos ${ }^{4}$. El director era el plenipotenciario de la Expedición. Ya desde 1801 había sido uno de los mayores defensores de la vacunación. Estudia sobre el tema. En sus estudios percibe la dificultad que tienen los médicos de habla exclusivamente hispana para entrar en contacto con las fuentes que describen el nuevo método preventivo contra las viruelas. Esta inquietud de acercar los nuevos conocimientos científicos a la mayoría de los sanitarios, le obliga a traducir la obra de Moreau de la Sarthe 5 .

Junto con la valía profesional nos encontramos la valía personal. Hombre metódico, minucioso, delicado, responsable, astuto, abnegado... Estas cualidades, innatas y cultivadas, le permitieron junto con su madurez personal dirigir y conseguir con éxito la Real Expedición. Balmis es un ejemplo de burócrata ilustrado al servicio de la sanidad. Y era consciente de que su labor profiláctica supondría la primera hazaña preventiva en la historia de la vacunología.

El director solo no hubiera podido realizar esta Expedición de dimensiones mundiales. Necesitaba un grupo de sanitarios (ayudantes, enfermeros y practicantes) que trabajasen sin descanso, que se dejaran la vida en la consecución del objetivo, que no escatimasen esfuerzos para lograr los fines y que fueran personalidades íntegras, comprometidas, trabajadoras y vocacionadas por la salud pública. Además el grupo estaba formado por una mujer, que es considerada la primera enfermera de la historia de la medicina hispana. Esta mujer cuidaba, acompañaba, entretenía, serenaba... a los niños en las largas travesías marítimas. Primero en el Atlántico y después en el Pacífico.

Balmis valoró su trabajo con estas palabras:

«La miserable Rectora que con el excesivo trabajo y rigor de los diferentes climas que hemos recorrido, perdió enteramente su salud, infatigable noche y día ha derramado todas las ternuras de la más sensible Madre sobre los 26 angelitos que tiene a su cuidado, del mismo

4 Las obligaciones específicas de cada cargo están reflejadas en el Expediente 1. Extracto General de la Expedición Filantrópica de la Vacuna. AGI: IG, 1558-A.

5 Moreau De la SARTHE, J.L. (1803): Tratado histórico y práctico de la vacuna (que contiene en compendio el origen y los resultados de las observaciones y experimentos sobre la vacuna, con un examen imparcial de sus ventajas, y de las objeciones que se le han puesto, con todo lo demás que concierne a la práctica del nuevo modo de inocular). Traducido y Prologado por Francisco Xavier de Balmis, Imp. Real, Madrid. 
modo que lo hizo desde La Coruña y en todos los viajes y los ha asistido enteramente en sus continuadas enfermedades $»^{6}$.

La colecta de los niños que sirvieron de reservorios humanos era difícil. Las familias perfectamente estructuradas no querían dejar a sus hijos para una aventura de la que no se sabían las consecuencias. Esta realidad obligó a conseguir los niños en las inclusas y en familias desestructuradas social y/o económicamente. Madres solteras o abandonadas o matrimonios con escasos recursos fueron los que dejaron a sus hijos para realizar esta campaña al servicio de la salud, aunque siempre se preferían niños que no tuviesen lazos familiares conocidos. A cambio, a estos niños se les hospedará y cuidará a cargo del Erario Público, «serán bien tratados, mantenidos y educados, hasta que tengan ocupación o destino con que vivir, conforme a su clase y devueltos a los pueblos de su naturaleza, los que se hubiesen sacado con esa condición» ${ }^{7}$. Aunque las promesas de la Corona eran tentadoras, la incertidumbre de lo desconocido envolvía a las familias. Las madres eran reacias a dejar a sus criaturas. Por ese motivo la organización centró sus preferencias en niños que no tuvieran padres conocidos.

No todos los niños servían para transportar la vacuna. Debían ser unos niños sanos, que no hubieran pasado las viruelas naturales y de menos de diez años. La elección de la calidad y la cantidad de los niños recaía directamente en Balmis.

\section{LA EXPEDICIÓN PARA PROPAGAR LA VACUNA}

La ruta propuesta no fue única. A medida que avanzaban los preparativos de la Expedición, se conocían mejor las necesidades y se cambiaba el derrotero. Se propusieron al menos tres rutas diferentes ${ }^{8}$ : la del Dr. Francisco Requena ${ }^{9}$, la del

6 Informe de Balmis a José Antonio Caballero, fechado en Macao el 30 de enero de 1806, f. 4-4v. AGI: IG, 1558-A.

7 Circular para la propagación de la Vacuna, fechada en San Ildefonso el 1 de septiembre de 1803. AGI: IG, 1558-A.

8 RAMÍREZ MARTín (1999), pp. 210-216.

9 El Dr Requena, cirujano de Cámara, propone que se manden a Ultramar «dos barcos habilitados con este solo fin, aunque es un gasto muy elevado merece la pena con el bien que se debía esperar». Informe de la Junta de Cirujanos de Cámara, fechado en Madrid el 17 de marzo de 1803. AGI: IG, 1558-A. 
Dr. José Flores ${ }^{10}$ y la del Dr. Francisco Xavier Balmis ${ }^{11}$. Con todas estas propuestas, el Consejo de Indias, el 26 de mayo de 1803, dictaminó una ruta para la Expedición ${ }^{12}$. La realidad es que ninguno de los derroteros propuestos es seguido por Balmis. Las modificaciones que se hacen sobre la marcha están motivadas por la necesidad de propagar con rapidez la vacuna con el fin de frenar las epidemias que se desencadenan en el territorio americano.

La Expedición no puede ser estudiada como una sucesión lineal de acontecimientos. El punto de inflexión que impide este estudio es la división que sufre al salir de la Capitanía General de Venezuela. Este hecho hace que en el mismo tiempo se dé una superposición de personas y de espacios. Para evitar esta dificultad en el estudio, prefiero asumir la división tradicional que sigue la obra de Gonzalo Díaz de Yraola $^{13}$. Este autor divide la Expedición en tres tramos: Expedición Conjunta, Expedición de Balmis y Expedición de Salvany.

La Expedición salió de Madrid el 7 de septiembre de 1803. Dos semanas más tarde, el 21 de septiembre ya están establecidos en La Coruña. En este puerto peninsular, Balmis prepara la travesía marítima del Atlántico. En los meses de octubre y noviembre se contrata el barco y se colectan en Galicia los niños que iban a transportar la vacuna en sus brazos.

La Expedición conjunta cronológicamente se desarrolla desde el 30 de noviembre de 1803 al 8 de mayo de 1804 . Después de más de dos meses de preparativos, la Expedición zarpa del puerto de La Coruña el 30 de noviembre de 1803, a bordo de la corbeta «María Pita», con dirección al archipiélago canario. El 9 de diciembre, a las 8 de la noche, la Real Expedición arriba al

10 El médico guatemalteco Flores propone que «se despache de Cádiz dos barcos ligeros que conduxesen algunas vacas con viruelas verdaderas, y algunos jovenes inoculados succesivamente en los brazos, llevandose ademas el pus escogido entre dos cristales cerrados con extremo cuidado, dirigiendose uno de los barcos a la Habana para introducir desde allí la vacuna en Puerto Rico, Truxillo, Yucatan y Veracruz, y el otro a Cartagena de donde se surtirá a Santa Fe, la Guayra, Montevideo, Portobelo, Panamá y demas provincias meridionales». Expediente 1. Extracto General de la Expedición Filantrópica de la Vacuna. AGI: IG, 1558-A.

11 Balmis propone que la Expedición de la Vacuna «debería ir destinada a los quatro virreynatos de América e islas Filipinas, haciendo estaca en Canarias y Puerto Rico, de donde pasaría a la Guayra y Caracas, y de aquí á La Habana, Yucatan, Campeche y Veracruz. Yntroduciendo la vacuna en este puerto en Xalapa, la Puebla y México, se dividirán los individuos de la expedición de acuerdo con el Virrey, para recorrer los varios distritos de Nueva-España, reuniendose después en Mexico para pasar al Perú, y de aquí a Chile y Buenos-Aires». Expediente 1. Extracto de la Vacuna en Ultramar, fechado en Cádiz el 12 de marzo de 1813. AGI: IG, 1558-A.

12 Dictamen del Gobernador del Consejo de Indias. Expediente para extender en América el uso de la Vacuna, fechado en Madrid el 26 de mayo de 1803. AGI: IG, 1558-A.

13 DíAZ de YRAOla (2003). 
puerto de Santa Cruz de Tenerife después de 10 días de navegación ${ }^{14}$. Los expedicionarios estuvieron en esta isla canaria escasamente un mes. Durante este tiempo realizaron tres vacunaciones generales en las que se trasmitía la vacuna a toda persona que lo demandaba. Cuando Balmis pensó que su labor había concluido, se dispuso la salida para no demorar la llegada a América. La Expedición abandonó Tenerife el día 6 de enero de 180415.

Después de una penosa travesía por el Atlántico, la Expedición llega sin novedad a la isla de Puerto Rico el día 9 de febrero del mismo año. El gobernador portoriqueño Ramón de Castro permaneció al margen y no se implicó en el devenir de la Expedición. Inicialmente, la fecha calculada para la salida de la isla fue el día 2 de marzo, pero «la falta de vientos favorables» originaron un retraso de más de 10 días ${ }^{16}$. Esto incrementó el problema de los niños necesarios para el mantenimiento del fluido fresco. Finalmente, los expedicionarios, a bordo de la María Pita, abandonan la isla portorriqueña con dirección a La Guayra el día 13 de marzo de 1804.

Las dificultades de la travesía y el desconocimiento de la marinería de esta costa provocaron que el barco arribase con urgencia en la ciudad de Puerto Cabello, el día 20 de marzo de 1804. Esta población caribeña estaba muy distante de donde les esperaban. Tardaron en llegar a Caracas más de 10 días. El día 30 de marzo de 1804, viernes santo, Balmis vacuna por primera vez en Caracas a 64 personas.

El Gobernador y Capitán General Manuel Guevara y Vasconcelos fue un gran defensor y propagador de la vacuna en los territorios de su gobierno. Una vez establecida la vacuna en Caracas, se envió a otros territorios de la Capitanía caraqueña: Coro, Puerto Cabello, Ortiz, Santa María de Iripe, Tocuyo, Maracaibo, Cumaná e isla Margarita.

En este territorio, con el visto bueno del Capitán General de Caracas, Balmis creó la primera Junta de Vacuna del continente americano el día 23 de abril de 1804.

La presión de la epidemia de viruela que se había generalizado en Nueva Granada aumenta el entusiasmo y obliga a Balmis a dividir la Expedición en dos para diversificar los esfuerzos y dar mayor rapidez a la propagación ${ }^{17}$. Una

14 Informe de la Junta Superior de Medicina, fechado el 26 de mayo de 1804. AGI: IG, 3163.

15 Gaceta de Madrid, viernes 10 de mayo de 1804.

16 Carta firmada por Salvany, Vice-director por indisposición del Director, dirigida al Capitán General de la isla de Puerto Rico, Ramón de Castro, fechada a bordo de la corbeta «María Pita», el 6 de marzo de 1804. AGI: Santo Domingo, 2322.

17 Carta de Balmis dirigida al Marqués de Someruelos, Capitán General de la isla de Cuba, en la que expone los motivos de la tardanza y de la división de la Expedición, fechada en La Habana el 26 de mayo de 1804. AGI: Cuba, 1691. 
parte, dirigida por Balmis, puso rumbo a la América Septentrional, y otra, dirigida por Salvany, a la América Meridional. Esta decisión retardó el abandono del territorio caraqueño, que se verificó el día 8 de mayo de 1804 .

La Expedición dirigida por Balmis toma rumbo a la América Septentrional. Cronológicamente la Expedición abarca desde el 8 de mayo de 1804, día de la separación de la Expedición en dos partes, hasta el 7 de septiembre de 1806, fecha de la llegada de Balmis a Madrid. Esta rama de la Expedición estaba compuesta por 6 personas: el director, Balmis; un ayudante, Antonio Gutiérrez Robredo; un practicante, Francisco Pastor; dos enfermeros, Pedro Ortega y Antonio Pastor; y la rectora, Isabel Sendales y Gómez. Además se les unían todos los niños que procedían de Galicia.

A bordo de la María Pita, la navegación por el Caribe fue difícil y alteró tanto la salud de los niños como la de los expedicionarios. Finalmente, la corbeta fondeó en el puerto de La Habana el 26 de mayo de 1804. A su llegada, Balmis descubre que la vacuna estaba perfectamente establecida por el médico Tomás Romay ${ }^{18}$. Ante la estupenda labor realizada por Romay, Balmis piensa que quedarse más en la isla sería una pérdida de tiempo e impediría llegar a otras regiones en las que no se conociera el fluido vacuno. El 29 de mayo, solicita que «se le proporcionen quatro niños que sirvan para trasmitir la preciosa vacuna» ${ }^{19}$. La solicitud no fue atendida. El día 14 de junio, después de tres semanas de ruegos, peticiones y solicitudes formales, comunica al Capitán General de la Isla, el Marqués de Someruelos, que no necesita los niños. Había convencido a un joven «tamborcito» del regimiento de Cuba y había comprado tres esclavas negras para que llevasen la vacuna a Nueva España. El viaje no se demora más. Una vez solventado el problema del transporte de la vacuna, la Expedición zarpa del puerto de La Habana cuatro días más tarde, el 18 de julio de 1804, con dirección a la península de Yucatán.

La Expedición arriba al puerto de Sisal, el 25 de junio de 1804. Cuatro días más tarde, los expedicionarios llegaron a la ciudad de Mérida. Ese mismo día comenzaron las vacunaciones en la ciudad con el apoyo de las autoridades locales. Ante este entusiasmo, Balmis decide propagar la vacuna por Centroamérica. Para realizar esta campaña, el director comisiona a su sobrino, Francisco Pastor ${ }^{20}$.

18 «En la Habana, el Dr. D. Tomás Romay propagó con feliz éxito y aprobación del Protomedicato la vacuna llevada a quellas islas por dña. María Bustamante». Expediente 1. Extracto General de la Expedición Filantrópica de la Vacuna. AGI: IG, 1558-A.

19 Carta de Balmis dirigida al Capitán General de la Isla de Cuba, Marqués de Someruelos, fechada en La Habana el 29 de mayo de 1804. AGI: Cuba, 1691.

20 RAMÍREZ MARTín (1999), pp. 357-359. 
El resto de los expedicionarios parten del puerto de Sisal con rumbo a Veracruz el día 19 de julio de 1804. La Expedición llegó al puerto veracruzano cuatro días mas tarde. En esta ciudad la vacuna estaba perfectamente establecida, gracias a la vacunación previa realizada por el Dr. Arboleya ${ }^{21}$. Esto disgustó muchísimo a Balmis, porque no encontró gente que se quisiese vacunar, y para mantener el fluido fresco hubo de recurrir a la tropa.

Alejado del centro de poder novohispano, Balmis había notado el desinterés del virrey por el tema de la vacuna. Le había mandado cartas solicitando órdenes de actuación para propagar la vacuna en su virreinato y no había recibido respuesta alguna. La indignación de Balmis era tan grande que remitió un artículo a la Gazeta de México «para que supiese que ya estaba introducida allí la vacuna» ${ }^{22}$. Ante tanta desidia, Balmis abandonó la ciudad-puerto de Veracruz el día 1 de agosto de 1804 con rumbo a la capital novohispana. Tenía prisa por llegar a la ciudad de México para «entregar los 22 niños que había sacado de la Coruña, quedando así desembarazado para acudir a donde se tuviere por conveniente» ${ }^{23}$.

La Expedición llega a la ciudad de México a las 10 de la noche del día 9 de agosto de 1804. La llegada a la capital no mejoró las relaciones del virrey Iturriagaray y Balmis, sino que se enconaron aún más. El enfrentamiento fue directo y no epistolar como hasta entonces. Para suavizar la situación, Balmis abandona la capital novohispana. Los expedicionarios tomaron rumbo al norte. Comenzaron las vacunaciones sistemáticas en Puebla de los Ángeles, Guadalajara de Indias, Zacatecas, Valladolid, San Luis Potosí, y las Provincias Internas. Durante este periplo se colectan los niños que van a llevar la vacuna por el Pacífico sin el control directo del virrey. Consiguieron 26 niños mexicanos para esta misión.

Terminada la labor y después de 53 días de ausencia de la capital novohispana, el 30 de diciembre de 1804, la Expedición vuelve a la ciudad de Méxi-

21 «Certifico que cerciorado el Exmo Sr. Virrey del merito cortraido por el Profesor Médico y Cirujano $1^{\circ}$ de la Armada D. Alexandro Arboleya en el establecimiento y propagacion dela Vacuna asi en esta Capital como en los Pueblos de otras Provincias de este Reyno se sirvio recomendarlo á S.M.». Certificado de las Campañas de Vacunación realizadas en México, fechado en México el 14 de diciembre de 1808. Archivo General de la Armada, D. Alvaro de Bazán, Viso del Marqués. Sección: Cuerpo de Sanidad, Leg. 2898-60, Exp. Alejandro García de Arboleya.

22 Expediente 18. Extracto General de la Expedición filantrópica de la Vacuna. AGI: IG, 1558-A.

23 Expediente 18. Extracto de la Vacuna en Ultramar, fechado en Cádiz el 12 de marzo de 1813. AGI: IG, 1558-A. 
co. La segunda estancia en la capital de la Nueva España fue corta porque inmediatamente comenzaron los preparativos para emprender el viaje que permitiese propagar la vacuna en el archipiélago filipino.

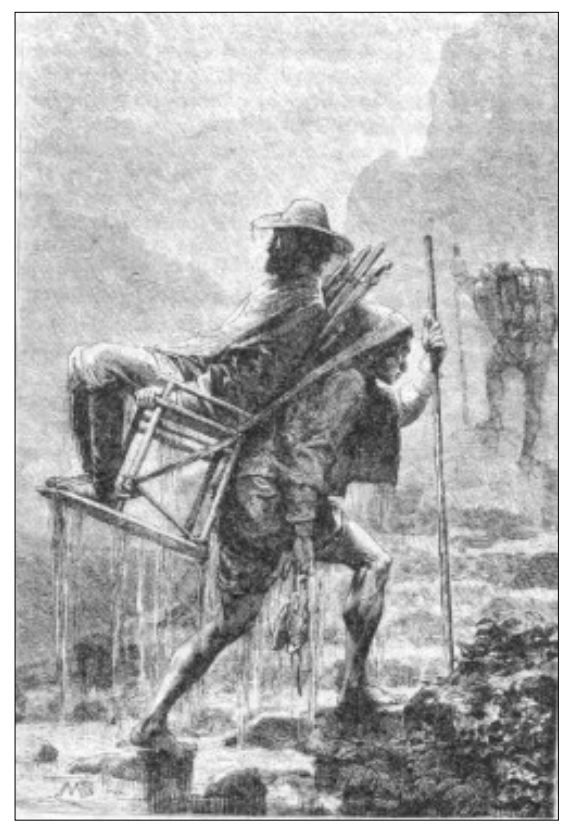

Carguero con silla

En los primeros días del año 1805, Balmis inicia las negociaciones para saltar a Filipinas. Balmis no cuenta con el apoyo del virrey. Después de un montón de impedimentos, la Expedición zarpa rumbo a las Filipinas el día 7 de febrero de 1805 a bordo del navío Magallanes. El viaje por el océano Pacífico no fue mejor que el viaje por el Atlántico. Mientras que para cruzar el Atlántico se había fletado un barco a propósito para la Expedición, para la travesía por el Pacífico la Expedición se tuvo que adaptar a una nave de línea regular: el Galeón de Manila o la Nao de Acapulco. Las condiciones de la navegación en nada se parecen a las pactadas en Acapulco. Balmis se queja por dos causas. Una, el mal trato dado a los niños, en los que residía el éxito o el fracaso de la Expedición. «Estuvieron mui mal colocados en un parage de la Santa Bárbara lleno de inmundicias y de grandes ratas que los atemoriza- 
ban, tirados en el suelo rodando y golpeándose unos a otros con vayvenes» ${ }^{24}$. Otra, el alto coste de los pasajes ${ }^{25}$.

Los expedicionarios llegaron a Manila el día 15 de abril de 1805. Las vacunaciones comenzaron al día siguiente. El método seguido para propagar la vacuna en el archipiélago fue radial y progresivo:

«se dió principio a la trasmision de la Vacuna, en todos mis hijos y continuo esta operacion en toda la capital, pueblos extramuros, y sucesivamente en las Provincias inmediatas; despues se acudió a las mas distantes, y en la estacion oportuna salieron para las provincias ultramarinas el Practicante D. Francisco Pastor y el Enfermero D. Pedro Ortega, llavando consigo el competente numero de jovenes para conservar la vacuna durante la navegacion ${ }^{26}$.

Balmis, persona de edad y aquejada de una gastroenteritis, casi desde el inicio de la Expedición, ve peligrar su vida. Como consecuencia de los enfrentamientos con el virrey Iturriagaray decide regresar «solo» a la Metrópoli por vía portuguesa desde Macao. A partir de este momento, la dirección de la Expedición por territorio filipino se transfiere a Gutiérrez Robredo. Los enfermeros Antonio Pastor y Pedro Ortega son comisionados por Balmis para llevar la vacuna a las islas de Misami, Zambuanga, Zebú y Mindanao ${ }^{27}$, mientras que el ayudante Gutiérrez Robredo permanece en Manila ${ }^{28}$. El grupo de expedicionarios que quedan en Filipinas tienen como misión la propagación del fluido por el archipiélago.

«Luego que mis compañeros concluyan sus viajes deben regresar en la Nao de Acapulco y devolver a sus padres los 26 Niños mexicanos» ${ }^{29}$.

El viaje que trae de regreso al director de la Expedición a la península Ibérica comienza cuando parte de Manila el 3 de septiembre de 1805. La nave-

24 Expediente 24. Extracto General de la Expedición filantrópica de la Vacuna. AGI: IG, 1558-A.

25 RAMÍREZ MARTÍN (1999), pp. 370-371.

26 Informe del Gobernador de Filipinas, Rafael García de Aguilar, dirigido a José Antonio Caballero, fechado en Manila el 24 de diciembre de 1805. AGI: IG, 1558-A.

27 Informe del Gobernador de Filipinas, D. Rafael García de Aguilar, dirigido a José Antonio Caballero, fechado en Manila el 24 de diciembre de 1805. AGI: IG, 1558-A.

28 Informe de Balmis a José Antonio Caballero, fechado en Manila el 31 de agosto de 1805. AGI: IG, 1558-A.

29 Informe de Francisco Xavier Balmis dirigido a José Antonio Caballero, fechado en Macao el 30 de enero de 1806. AGI: IG, 1558-A. 
gación por esta zona no era fácil. Asolaban la zona constantes huracanes y ataques de piratas chinos. Balmis llega a Macao a bordo de la fragata Diligencia el 16 de septiembre. El recibimiento de la vacuna en Macao fue extraordinario, contó con el apoyo de las autoridades locales. Una vez establecida la vacuna en esta factoría, Balmis se dirige hacia la población de Cantón, el día 5 de octubre de 1805 .

En el mes de febrero de 1806, Balmis abandona Asia, a bordo del navío portugués Buen Jesús di Alem, que hace la ruta Macao - Lisboa. Este barco no realiza una ruta directa, sino que tiene una escala técnica en la isla británica de Santa Elena. Después de seis meses de navegación, Balmis llega al puerto de Lisboa en la tarde del día 14 de agosto de 1806. El director de la Real Expedición Filantrópica de la Vacuna besó la mano del rey Carlos IV en Madrid el día 7 de septiembre de 1806. Por este hecho, algunos historiadores de la ciencia, dan por terminada la Expedición. Pero la realidad no era esa. El resto de los expedicionarios de esta ruta no llegarán a Acapulco hasta el 14 de agosto de 1809. Ninguno de ellos consiguió volver a la Península, y las próximas guerras (Independencia española e Independencia americana) les obligaron a establecerse en Ultramar ${ }^{30}$.

La Expedición dirigida por Salvany se encamina a América Meridional. Cronológicamente abarca desde la separación de la Expedición, el día 8 de mayo de 1804, hasta el día de la muerte de Salvany, el 21 de julio de 1810. Esta rama de la Expedición estaba compuesta por 4 personas: el subdirector, que a partir de ese momento tendría cargo de director, José Salvany; un ayudante, Manuel Julián Grajales; un practicante, Rafael Lozano Pérez; y un enfermero, Basilio Bolaños. $Y$ cuatro niños que se encargarán de transportar la vacuna en sus brazos.

La división era «fácil» en teoría, pero la práctica generó problemas. Para trasladar a los expedicionarios desde La Guayra a Cartagena, se contrató al bergantín «San Luis». Pero no se podía empezar peor. El día 13 de mayo de 1804, a los cinco días de comenzar su periplo, el barco encalló en las bocas del río Magdalena cerca de la ciudad de Barranquilla. Todos los expedicionarios se vieron afectados. Viendo el riesgo que corrían, «desembarcaron precipitadamente en una playa desierta á barlovento de Cartagena» ${ }^{31}$. Su vida estuvo en peligro. No fallecieron porque contaron con la ayuda de los naturales y de un navío de corso, La Nancy, al mando del teniente de navío Vicente Varela, que viajaba por ese tramo del río $^{32}$. El incidente les había alejado del

30 Smith, M. (1974), The «Real Expedición Maritima de la Vacuna» in the New Spain and Guatemala, Transactions of the American Philosophical Society, Philadelphia, p. 68.

31 Carta del Virrey Amar dirigida a José Antonio Caballero, fechada el 19 de julio de 1804. AGI: IG,1558-A. 
rela, que viajaba por ese tramo del río ${ }^{32}$. El incidente les había alejado del derrotero establecido por Balmis. Para retomar la ruta prevista tuvieron que atravesar "por el desierto a la Cienagas de Santa Marta y desde allí a Cartagena» ${ }^{33}$. La Expedición no sufrió pérdidas humanas pero tuvo muchas pérdidas materiales, sobre todo los instrumentos de vacunación.

La llegada de la Expedición a Cartagena estuvo enmarcada entre la necesidad, amenazaba una epidemia de viruelas naturales, y el entusiasmo de sobrevivir al naufragio. En esta ciudad, los expedicionarios contaron con el apoyo político de las autoridades locales, pero también con el económico del potente Consulado cartagenero, que financió todos sus gastos ${ }^{34}$. La Expedición contó en Cartagena con el apoyo de su Gobernador, Cejudo, que, incondicionalmente, facilitó su labor vacunadora por el territorio de su mando.

Rápidamente, Cartagena se erigió en un centro difusor de la vacuna. Desde esta población se irrigó el fluido siguiendo dos caminos. Uno, hacia Panamá por Portobello, a cargo de un religioso bethlemita acompañado de cuatro niños. Otro, hacia Buenos Aires por Riohacha, que llevaba la vacuna entre cristales. Cuando Salvany consideró que ya estaba establecida la vacuna en esos territorios, preparó el viaje para continuar su campaña de salud pública rumbo a Santa Fe de Bogotá. Salieron de Cartagena el día 24 de julio de 1804, y, les acompañaban diez niños, que conservarían el fluido fresco en sus brazos, y las comunicaciones oportunas que ordenaban «a las justicias de los pueblos por donde transitasen para que le auxiliasen en quanto se le ofreciese» ${ }^{35}$. La navegación por el Magdalena era tranquila, aunque larga y penosa. Se realizó en pequeños barcos muy ligeros que se llamaban «campanes».

Durante la travesía, Salvany se dio cuenta de la envergadura de la Expedición. Era mucho territorio para sólo cuatro hombres. Para no dispersar esfuerzos, y siguiendo el criterio que había ideado Balmis, se dividen las fuerzas para abarcar mayor porción de territorio. Se crearon dos grupos, cada uno de ellos formado por dos facultativos. Los grupos variarán a lo largo del recorrido en función a las necesidades de la propagación de la vacuna. Antes de lle-

32 Carta de Miguel Antonio de Yrigoyen dirigida a Domingo Gandallana, fechada en Cartagena el 26 de junio de 1804. Archivo General de la Armada Álvaro de Bazán, Viso del Marqués, Expediciones a Indias, Leg. 36.

33 Informe sobre los servicios distinguidos prestados. Archivo General Militar de Segovia. Sección $1^{\text {a }}$ : Expedientes Personales, G-3848.

34 Carta del Gobernador de Cartagena, Cejudo, dirigida a José Antonio Caballero, fechada el 18 de agosto de 1804. AGI: IG, 1558-A.

35 Expediente 19. Extracto General de la Expedición filantrópica de la Vacuna. AGI: IG, 1558-A. 
gar a Santa Fe, la Expedición pasó por las poblaciones de Tenerife, Mompox, Ocaña, el valle del Cucutá, Pamplona, San Gil, Socorro, Velez, Nares, Hon$\mathrm{da}^{36}$. En esta ciudad Salvany tuvo que descansar porque se encontraba aquejado de sus males, que se habían agravado en el ascenso de los Andes.

Enterado de la enfermedad de Salvany, el virrey Amar se alarmó. Con temor de que la vacuna no llegase a la capital del Virreinato, por la posible muerte de Salvany, dispuso la salida de Santa Fe de «un facultativo y niños, con los demas socorros necesarios tanto para su curación como para que dicho facultativo se hiciese cargo de la conservación del fluido si llegaba á morir Salvany» ${ }^{37}$. Salvany superó la enfermedad y llegó a la capital neogranadina el 17 de diciembre de 1804 .

Los desastres de la viruela en esta capital habían creado una opinión pública favorable a la vacuna. Las vacunaciones comenzaron al día siguiente, el 18 de diciembre de 1804. El apoyo del virrey neogranadino fue esencial. Hizo conocer la llegada de la Expedición por bando. Publicó en la Imprenta Real santaferina un «Reglamento para la conservación de la Vacuna en el Virreinato de Santa Fe» ${ }^{38}$. Facilitó una sala del hospital que estaba al cargo de los religiosos de San Juan de Dios, aunque Salvany rechazó la propuesta, para que no se relacionase la vacuna con la idea de enfermedad y muerte ${ }^{39}$. La Expedición también contó con el apoyo de las autoridades eclesiásticas. Los párrocos desde los púlpitos recomendaron el uso de la vacuna y exaltaron la personalidad de Salvany y sus colaboradores.

La estancia en Santa Fe sirvió para reponer fuerzas, tanto físicas como psíquicas. Resultaba gratificante parar, detener la agitada marcha, poder reposar de las difíciles y peligrosas andaduras por valles y quebradas. No menos agradables fueron el júbilo y el aplauso con que los recibieron ${ }^{40}$. El día 8 de marzo de 1805, la Expedición abandona Santa Fe con dirección al Virreinato

36 RAMÍREZ MARTíN (1999), pp. 386-387.

37 Expediente 19. Extracto General de la Expedición filantrópica de la Vacuna. AGI: IG, 1558-A.

38 Martínez ZulaicA, A. (1972), La medicina del siglo XVIII en el Nuevo Reino de Granada, de Europa a América a través del filtro español. Una gesta y un drama, Universidad Pedagógica y Tecnológica de Colombia. Ed. «La Rana y el Águila», Tunja, pp. 246-247.

39 «Los aires nocivos que se respiran en los hospitales podían atrasar y desacreditar la vacuna, que tan rápida como felizmente se había propagado hasta entonces». Expediente 19. Extracto General de la Expedición filantrópica de la Vacuna. AGI: IG, 1558-A.

40 Informe de la Junta de Medicina, fechado en Madrid el 6 de junio de 1807, en Expediente 19. Extracto General de la Expedición filantrópica de la Vacuna. AGI: IG, 1558-A. 
peruano, después de haber realizado 56.324 vacunaciones. La magnitud de la cifra hace pensar en la intensidad de la labor profiláctica desarrollada.

A la salida de Santa Fe, la Expedición se divide en dos. Una, al mando de Grajales, a quien acompaña el enfermero Bolaños, atravesando las montañas del Quindío, se dirige a la ciudad de Neiva y La Plata hasta Popayán. Y la otra, al mando de Salvany, a quien acompaña el practicante Lozano, se dirige también con rumbo a Popayán pasando por las ciudades de Ybagué, Cartago, Truxillo, Llano Grande, Provincia de Choco y Real de Minas de Quilichas. El grupo Grajales-Bolaños llegó a Popayán en abril ${ }^{41}$ y el grupo Salvany-Lozano en mayo ${ }^{42}$. En Popayán, lo primero que tuvo que hacer la Expedición fue «reponerse de las fatigas de su viaje y del quebranto que advertía nuevamente en su salud con la misma enfermedad de ojos y efusión de sangre por la boca que había padecido en Santa Fe» ${ }^{43}$.

Salvany retarda la salida, pero no puede parar la propagación de la vacuna, sobre todo cuando recibe la noticia de que la Real Audiencia de Quito sufre una epidemia de viruelas naturales. Este es el detonante del abandono de Popayán. Hay que llegar al territorio quiteño cuanto antes. Salvany divide nuevamente la Expedición.

Grajales y Bolaños desde Popayán toman rumbo a la ciudad de Barbacoas para que desde allí, costeando Tumaco, La Tola y Jipijapa, lleguen a la ciudadpuerto de Guayaquil. Con el envío de la vacuna a Guayaquil, Salvany pretende que esta ciudad, además de ser un centro comercial, sea un centro difusor de la vacuna. Encomienda a Grajales que desde este puerto envíe la vacuna entre cristales en cualquier barco que se dirija al territorio panameño. Mientras tanto, Salvany y Lozano se desplazarían desde Popayán a Quito por la sierra. Pasarán por las poblaciones de Pasto, Tulcan, Ybarra, Otavalo y Cayambe.

Las previsiones pensadas para propagar la vacuna por la costa no se pudieron llevar a cabo, por la constante presencia de ingleses en la Isla de la Gorgona, en la bahía de Atacames, en el cabo de San Francisco y en la punta de la isla de Santa Elena ${ }^{44}$. Grajales y Bolaños llegan a Quito siguiendo el dificultoso camino de Malbucho.

41 Informe sobre los servicios distinguidos prestados. Archivo General Militar, Segovia. Sección $1^{\mathrm{a}}$ : Expedientes Personales, G-3848.

42 Expediente 19. Extracto de la Vacuna en Ultramar, fechado en Cádiz el 12 de marzo de 1813. AGI: IG, 1558-A.

43 Expediente 19. Extracto General de la Expedición filantrópica de la Vacuna. AGI: IG, 1558-A.

44 Comunicación del comisionado para la Vacuna D. Manuel Julián Grajales, informando al Presidente de la Audiencia las razones que tuvo para no llegar al Puerto de Guayaquil, 
El grupo encabezado por Salvany llega a Quito el 16 de julio de 1805 . Contó con el apoyo tanto de las autoridades civiles como eclesiásticas. La primera vacunación se verificó el día 3 de agosto de 1805. La estancia en la ciudad quiteña no es del todo perfecta. Poco antes del abandono de esta ciudad, al subdirector de la Expedición Vacunal le sustraen «100 pesos fuertes y parte de su equipaje ${ }^{45}$. Después de este lamentable acontecimiento, el lunes 13 de septiembre de 1805, la Expedición partió de Quito con dirección a Cuenca, pasando por las poblaciones de Latacunga, Ambato y Riobamba. Llegan a la ciudad de Cuenca el día 12 de octubre de 1805. Al día siguiente se celebró una misa con Te Deum de acción de gracias en la Catedral y al terminar se realizaron 700 vacunaciones. En la ciudad de Cuenca, las manifestaciones de acción de gracias fueron fastuosas y muy concurridas por la población ${ }^{46}$.

En Cuenca los expedicionarios estuvieron durante dos meses. La Expedición salió de Cuenca el 16 de noviembre de 1805 con dirección a la ciudad de Loja. Pasó por los pueblos de Cumbe, Nabón y Oña. Salvany enfermó de nuevo y necesitó el apoyo de un religioso bethlemita ${ }^{47}$.

El camino a Loja se realizó rápidamente. En el trayecto los expedicionarios vacunaron a 900 personas y en la ciudad a 1500 personas más. El tiempo que gastaron fue poco, porque la Real Expedición salió de Loja el 10 de diciembre de 1805 con dirección al territorio peruano.

Nuevamente llegan a oídos de los expedicionarios las noticias de las epidemias de viruelas en Lima. Aunque las condiciones del camino son malísimas, en la Expedición se impone la rapidez. El virrey Avilés reconoce la labor de Salvany en una situación pésima, cuando dice:

fechada en Quito el 12 de diciembre de 1805. Archivo Nacional de Historia, Quito. Sección: Presidencia de Quito, 1805, Caja 180, Libro 431, p. 153-155.

45 Oficio de Manuel Calixto Muñoz escribano público y del Cabildo dirigido al Barón de Carondelet, Sr. Alcalde de primer voto de esta capital, fechado en Quito el 7 de septiembre de 1805. Archivo Nacional de Historia, Quito. Sección: Presidencia de Quito, 1805, Caja 178, Libro 424, p. 189 hasta el final.

46 Paredes Borja, V. (1963), Historia de la Medicina en el Ecuador, Ed. Casa de la Cultura Ecuatoriana, Quito, vol. II, pp. 43-44.

47 «Consiguió que el padre bethlemita Fray Lorenzo Justiniano de los Desamparados le acompañase para cuidarlos como lo hizo, tratandoles con cariño y esmero, incluso ayudó a Salvany a practicar algunas vacunaciones». Expediente 19. Extracto General de la Expedición filantrópica de la Vacuna. AGI: IG, 1558-A. 
«Entró Salvany en el Virreynato del Perú viajando con la presteza que permitía la Cordillera de los Andes en la estación más rigurosa de lluvias y nieves, falta de caminos, y la necesidad de cortar el contagio de viruelas en los más de los pueblos» ${ }^{48}$.

Desde el 23 de diciembre de 1805 hasta el 9 de enero de 1806, la Expedición estuvo en Piura. Después pasaron por Lambayeque, Cajamarca y Truji$110^{49}$. Por el camino tacharon a Salvany de «Anticristo» 50 y unos arrieros abandonaron a los expedicionarios cerca del Mineral de Chota.

Cuando Salvany llega a Lima, se comerciaba con la vacuna. Se compraba y se vendía como el aguardiente o la sal. La vacuna no estaba controlada por facultativos, sino por comerciantes, que veían en este fluido un modo rápido y seguro de enriquecerse. Ante este hecho generalizado y mantenido por la población limeña, Salvany no puede actuar. Se siente incapaz de transformar esta realidad. Desilusionado, abandona las vacunaciones en masa, más o menos generalizadas. No lucha contra la realidad vacunal establecida, sino que intenta transformarla.

Salvany dedica todas sus maltrechas fuerzas a la elaboración de un reglamento, que organice todas las campañas, métodos, planes... de vacunación y sea común para todo el Virreinato peruano. La estancia de la Expedición en Lima fue larga y Salvany descansa del agotador viaje. Deja las vacunaciones en manos de facultativos experimentados. Tiene mucho tiempo libre. Estudia y piensa. Se vincula a la elite intelectual de la Universidad de San Marcos y a las tertulias ilustradas, que, a imagen de la metrópoli, se celebraban en las casas de las elites criollas.

Antes de salir de Lima, Salvany encomienda a Grajales dos expediciones regionales. Una con dirección al Cuzco y otra con rumbo a la Capitanía General de Chile ${ }^{51}$. Salvany continúa el camino con dirección a Buenos Aires. Sale de Lima el 15 de octubre de $1807^{52}$ con dirección a la ciudad de Arequipa. El viaje desde la costa (Lima) a la sierra (Arequipa) agravará de nuevo la dañada salud de Salvany. La altura y los fríos de la sierra afectan a la enfermedad

48 Resumen que hace el Virrey Avilés sobre la Expedición de la Vacuna, fechado en Lima en el mes de julio de 1806, f. 1. AGI: IG, 1558-A.

49 RAMÍREZ MARTín (1999), p. 406.

50 Expediente 20. Extracto General de la Expedición filantrópica de la Vacuna. AGI: IG, 1558-A.

51 Informe sobre los servicios prestados. Archivo General Militar, Segovia. Sección 1a: Expedientes Personales, G-3848.

52 Resumen que hace el virrey Avilés, añadido con otra letra, fechado en Lima el 20 de septiembre de 1807, f. 3-3v. AGI: IG, 1558-A. 
pulmonar que padece. En este trayecto tarda casi dos meses. El día 8 de diciembre de 1807, llega a Arequipa enfermo. Todavía impresiona leer los síntomas que describen quienes lo vieron. El certificado médico dice:

«Se confundia con la Apoplegia por la intermitencia de su pulso, y por la respiración estertorosa precedida de movimientos convulsivos; y el síncope en su cesación, nos presentaba un espectáculo de horror» ${ }^{53}$.

Salvany pasa la Navidad de 1807 y recibe al año nuevo en esta ciudad. La estancia en Arequipa es reconstituyente. Pero la Expedición debe continuar propagando la vacuna y no puede demorarse eternamente en un lugar. Sale de Arequipa con dirección a la población situada a la mayor altitud de toda la cordillera andina, La Paz. El trayecto no es largo, pero está deshabitado. Las escasas poblaciones que existen por el camino carecían de facultativo y de remedios para mejorar la enfermedad que padecía el Subdirector. Con el tiempo, la salud de Salvany no mejora y su enfermedad se agrava. El día 1 de abril de 1809, por fin llega a la ciudad de La Paz, primera ciudad de la Real Audiencia de Charcas, que pertenece al Virreinato de Buenos Aires.

Después de dos semanas de total tranquilidad, en reposo absoluto, su salud no se restituye.

«Enfermedad de un afecto reumático de bastante consideración, el cual, como lo hemos observado, toma diversas formas, y presenta aspectos mas o menos graves según la sensibilidad o importancia de las partes en donde se fija, pues en el tiempo que le hemos tratado de diversos ataques ya en el vientre, pecho, y cabeza, le ha constituido en peligro con los graves síntomas con que ha venido acompañado, y siendo dicho afecto producido a nuestro parecer, por la variación de climas por donde le han conducido forzosamente sus dilatados viajes e indispensables fatigas que les son anejas, si continua mas tiempo variando temperamentos, sufriendo las molestias de caminos y exponiéndose a los contingentes indispensables de insolaciones, lluvias, y nieves, y al transito continuo de valles, cordilleras y rios, puede muy bien ocasionarle un accidente mortal, según lo que llevamos ya designado: por lo que juzgamos le sería mas conveniente a su existencia, fijar su residencia en un clima medianamente templado, sano y moderadamente seco» ${ }^{54}$.

Si de Arequipa a La Paz tarda más de 16 meses, de La Paz a Cochabamba, parecido trayecto, tarda 13 meses. Mejoran las condiciones climáticas pero no

53 Certificado médico firmado por el Bachiller Pablo José del Carpio, fechado en Arequipa el día 17 de diciembre de 1807. AGI: IG, 1558-A.

54 Certificado médico fechado en La Paz el 13 de abril de 1809. AGI: IG, 1558-A. 
la salud. Salvany mantiene el entusiasmo para propagar la vacuna, pero no le acompañan las fuerzas. El día 21 de mayo de 1810, desde la ciudad de Cochabamba, solicita el permiso al presidente de la Real Audiencia de Charcas para internarse y propagar la vacuna en las provincias de Mojos y Chiquitos ${ }^{55}$.

Dos meses más tarde, el día 21 de julio de 1810, Salvany muere en Cochabamba sin terminar la campaña de propagación de la vacuna por el territorio sudamericano.

\section{El LEGADO DE LA EXPEDICIÓN}

La expedición dirigida por Balmis y Salvany es la primera campaña vacunadora con dimensiones mundiales. No sólo duró desde 1803 a 1810, sino que el espíritu que la había originado se mantuvo en el tiempo en las sociedades a las que llegó. Esta onda sanitaria del establecimiento de la vacuna requería, además de unas lógicas exigencias sanitarias, unas implicaciones políticas y sociales comprometidas.

Políticamente, la llegada de la Expedición suscitó en muchos territorios enfrentamientos entre los poderes locales y el poder metropolitano. Las autoridades políticas ultramarinas experimentan una lucha entre los intereses de sus súbditos y el interés general del Estado. No se tienen claras las dimensiones de la identidad hispana y comienzan a despuntar los regionalismos en América.

Las epidemias de viruela afectaban por igual la choza de un indígena y el palacio del virrey o del arzobispo. La viruela afecta a toda la población. No es ilógico que desde que llegan a Ultramar las primeras noticias del descubrimiento de la vacuna, las autoridades locales americanas hicieran esfuerzos por que el recién descubierto preservativo contra las viruelas arribara a sus territorios. Desde los virreyes hasta los comerciantes se empeñaron en conseguir que la vacuna llagara a la mayoría de los territorios de Ultramar.

La regionalización de América dificultará los movimientos geográficos de los expedicionarios. El ejemplo más dramático lo experimentarán en el paso del Virreinato de Nueva Granada al Virreinato del Perú. La importancia geopolítica de los territorios está motivada primariamente por la potencia económica y comercial de los mismos. Esta realidad determinará y condicionará la propagación y el mantenimiento de la vacuna en los territorios a los que llega.

55 Carta de Francisco Ignacio de Medeiros, Presidente de la Real Audiencia de Charcas, dirigida al Rey, fechada en La Plata el 21 de mayo de 1810. Archivo Nacional de Historia, Sucre (Bolivia), Sección: Expedientes Coloniales 1810-14. 
Socialmente, la Expedición de la Vacuna no afecta por igual a la realidad americana, sino que cada territorio se empeña de diferente manera en el proyecto vacunal. La sociedad americana, desde la conquista, era compleja y mestiza, que se manifestaba con desigual intensidad frente a lo que acaecía. Ante un mismo acontecimiento, como las epidemias de viruela, la actitud de los grupos era diferente. No era lo mismo la actitud de los indígenas que la de los hispanos. El terror, el pánico y el miedo hacia la enfermedad sembraban la idea de desesperanza y muerte. Los indígenas eran los más desfavorecidos ante los brotes epidémicos. Como no tenían su sistema inmunológico preparado, los contagios eran masivos y más virulentos. Este modelo de respuesta social se manifiesta también con la llegada de la vacuna. Indígenas y criollos, militares y eclesiásticos, americanos y peninsulares se enfrentan al recién descubierto fluido de modo muy diverso ${ }^{56}$.

La opinión pública se ocupa y preocupa de las epidemias. Y el periodismo se encargará de difundir el nuevo descubrimiento y los experimentos vacunales tanto en la Península como en América. Estas noticias médicas saltarán a las Gacetas peninsulares y ultramarinas. A partir de 1801, en América se encuentran noticias sobre la vacuna y la vacunación en periódicos como Almanaque Peruano, Mercurio Peruano, Mercurio Volante, Gazeta de México, Gazeta de Guatemala, y Papel periódico de la Havana. Las noticias que recogen en sus páginas abordan diferentes temas. Por un lado, relatan y describen los efectos de las epidemias variolosas. Por otro lado, informan sobre las diferentes gestiones para introducir el fluido vacuno que se usa con éxito en Europa. Pero el aspecto que más prolijamente aparece en la prensa son los censos de vacunados y las crónicas de la Real Expedición Filantrópica de la Vacuna.

\subsection{Las Juntas de Vacuna}

Además de llevar la vacuna a Ultramar, hay que propagarla y perpetuarla. Para verificar estas dos acciones se crean las Juntas de Vacuna. Son instituciones locales establecidas en cada una de las principales poblaciones. Estas Juntas están reglamentadas por el mismo Balmis. Creó la Junta de Caracas y a imagen de esta se crearon todas las demás en América. Están jerarquizadas en función a la cantidad de población y a la importancia política de la ciudad en la que se establecen. Así encontramos dos tipos de Juntas de Vacuna: Centra-

56 RAMíREZ MARTín (1999), pp. 167-188. 
les y Subalternas. La relación entre ellas era dependiente y dentrítica: de la Junta Central dependían las Juntas Subalternas.

Este proyecto sirvió para institucionalizar la sanidad en América, que hasta ese momento recaía en las Órdenes sanitarias (judeandinos y bethlemitas), que con mayor o menor acierto ejercían la medicina en América a principios del siglo XIX. Estas Órdenes religiosas estaban establecidas en los territorios en función de las necesidades de la población y de la política en el momento de su fundación. Los centros sanitarios eran conventos-hospitales y el ejercicio de la medicina era eminentemente práctico. Los estudios médicos de estos monjes no salían de la lectura de su reducida biblioteca.

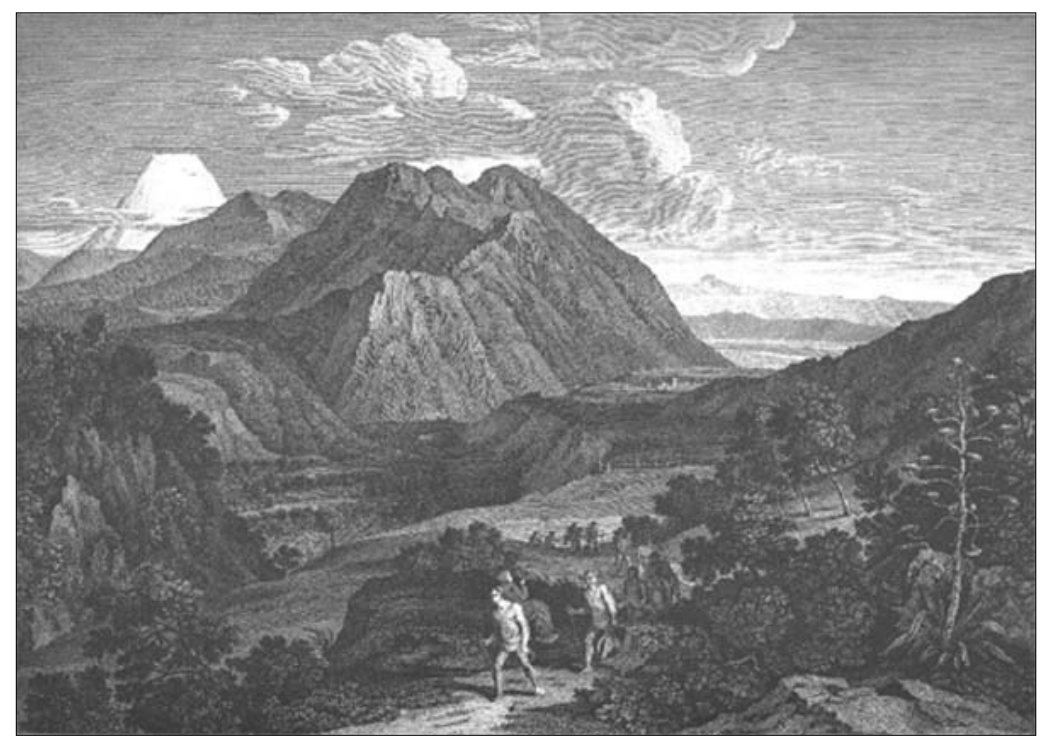

Indios en los Andes.

La Expedición de la Vacuna se apoyó en la urdimbre hospitalaria y en los sanitarios locales para propagar la vacuna con mayor difusión. Ejemplo significativo es el área andina y la alianza de los bethlemitas con el proyecto vacunal.

Las Juntas de Vacuna también tienen una proyección docente. Los médicos locales son necesarios para mantener la vacuna después de que los expedicionarios abandonaban sus territorios. Por eso hay que formar a los sanitarios locales en el ejercicio de la vacunación y crear monografías que expliquen el método y 
la práctica de la vacuna. Esta dimensión educativa recaía en la Juntas Centrales, que compilaban todo el saber acerca de la vacuna y los métodos de vacunación.

A su regreso a la península, Balmis reflexiona sobre el papel que juegan las Juntas de Vacuna en la perpetuación de la vacuna en los territorios a los que ha arribado la Expedición. Consecuencia de estos pensamientos, elabora dos escritos fechados el mismo día, el 12 de febrero de 1807. Uno, titulado «Reglamento para perpetuar en las Indias la Vacuna, del establecimiento de una Junta Central y Casa de Vacunación pública». Y otro, titulado «Reglamento para que se propague y perpetúe en España el precioso descubrimiento de la Vacuna». En estos escritos aparece perfectamente estructurada la institución que servirá para difundir y mantener el preservativo frente a las viruelas tanto en la Península como en Ultramar. En esencia los dos reglamentos son iguales, aunque se tiene en cuenta la diversidad geográfica.

Ya desde el comienzo de la gesta de la Expedición de la Vacuna, el objetivo de los expedicionarios era buscar los cauces para la propagación de la vacuna con mayor rapidez y amplitud. Para la consecución de estos objetivos se emiten reglamentos para la formación de las Juntas de Vacuna que tienen como encomienda la conservación y el cuidado del fluido vacuno.

La Circular del 1 de septiembre de 1803 establece lo siguiente:

«que en todas las Capitales, y en los pueblos principales del tránsito residirán los comisionados los días precisos para comunicar a los naturales y habitantes el fluido vacuno gratuitamente, enseñar la práctica de la operación a los Facultativos y demás personas, que quieran aprovecharse de esta oportunidad» ${ }^{57}$.

En consecuencia, el responsable de la creación de las Juntas de Vacuna era el director de la Expedición. Pero no sólo se encargó el director de la Expedición de la creación de todas las Juntas de Vacuna. Salvany, como subdirector, también creó la Juntas Centrales en la América Meridional. Y también tenía potestad para fundar las Juntas cualquier miembro de la Real Expedición comisionado para este fin. Por ejemplo, el ayudante Pastor fue comisionado por Balmis a Guatemala desde La Habana para establecer en la capital de la Capitanía una Junta de Vacuna con un reglamento parecido al de Caracas ${ }^{58}$.

Aunque el modelo de creación y establecimiento de Juntas de Vacuna seguido por Balmis en América fue la Junta de Vacuna de Caracas, el primer

57 Circular para la propagación de la Vacuna, fechada en San Ildefonso el 1 de septiembre de 1803. AGI: IG, 1558-A.

58 Cf. RAMíreZ MARTíN (1999), p. 425. 
proyecto de Junta de Vacuna y Reglamento de Vacunación se ensayó en Canarias. La primera Junta de Vacuna se estableció en Tenerife en una casa particular y tenía como objetivo la conservación perpetua y la comunicación del fluido a los naturales del archipiélago canario. Los facultativos de la Expedición dejaron formado un reglamento de gobierno de la Junta de Vacuna que fue complementado por el Comandante General de las Islas. Finalmente el documento fue sometido a la aprobación real.

Este Reglamento creado por Balmis para Canarias contó con el informe favorable y el visto bueno para su impresión en la Imprenta Real ${ }^{59}$. Un mes más tarde, el 25 de mayo de 1804, la Junta Superior de Medicina determina que el reglamento canario debería generalizarse a todas las Capitales. El 17 de junio de 1804, una vez aprobado el reglamento, la Junta Superior de Medicina lo remite al Consejo de Castilla para «que lo impriman, circule y encargue su execución con intervención de ella, y que en casos de duda, y de anomalías la consulte para resolverlas» ${ }^{60}$. Con el paso del tiempo, este matiz provocará enfrentamientos entre la Junta Superior de Cirugía y la Junta Superior de Medicina por no estar bien delimitadas sus competencias en los asuntos de vacuna.

El último paso llegó con la Real Orden fechada en San Lorenzo el 1 de octubre de 1804 en la que se dice:

«A ejemplo de lo que se ha hecho en Canarias al arribo de la expedición marítima destinada a propagar en sus Dominios de Indias el admirable descubrimiento de las vacunas. El Rey resuelve que en todos los hospitales se destine una sala para conservarlo y comunicarlo a cuantos concurran a disfrutar de este beneficio, y gratuitamente a los pobres, practicando hoy las operaciones por tandas periodicamente y en corto numero de personas proporcionado al de los que nazcan de ordinario en cada capital» ${ }^{61}$.

El contenido del Reglamento de la Junta de Vacuna de Canarias está inserto en un Informe de la Junta Superior de Medicina, fechado el 26 de mayo de $1804^{62}$. Éste constaba de dos partes: una económica y otra facultativa.

La económica determinaba que la casa debía estar abierta todo el año, habitada y aseada por una rectora y un portero que debían ser matrimonio.

$59 C f$. Carta del Rey a Pedro Cevallos, en la que informa de la aprobación del reglamento de Canarias y el visto bueno para su impresión en la Imprenta Real, fechada en Aranjuez el 20 de abril de 1804. AGI: IG, 3163.

60 Informe de la Junta Superior de Medicina, fechado el 26 de mayo de 1804. AGI: IG, 3163.

61 Real Orden fechada en San Lorenzo el 1 de octubre de 1804. AGI: IG, 3163.

62 Informe de la Junta Superior de Medicina, fechado el 26 de mayo de 1804. AGI: IG, 3163. 
Debía estar provista de cuatro camas donde pudiesen «morar los días precisos las personas que vayan a vacunarse de todas las Islas». También debía estar dotada de los utensilios necesarios para practicar las vacunaciones. La tesorería de la casa estaría a cargo del Cura Beneficiado de Santiago de Tenerife. Este prelado estaría encargado de «llevar razón de cuantas inoculaciones se hagan, y de dar cuentas al comandante general y al Ayuntamiento».

La parte facultativa se encargaría de que «las vacunaciones sean periódicas, y en sólo tres o cuatro personas a la vez». Como la maduración del pus vacuno se estimaba en nueve días, resulta que «en cada mes se executaran unicamente tres vacunaciones en 9 o 12 personas». Los destinatarios de estas vacunaciones deberían ser los niños recién nacidos, pero si escaseaban se podía vacunar a niños y personas de más edad. El fluido se comunicaría de brazo a brazo, además de conservarlo en vidrios. Junto a este control, los facultativos llevarían un diario con las novedades y posibles anomalías de cada individuo inoculado con el fin de establecer precauciones para el futuro.

El objetivo de la erección de las Juntas de Vacuna era «para no crear una mala opinión pública frente a la vacunación». Estas Juntas se suelen establecer en una casa destinada a este fin. El edificio «deberá tener sobre la puerta un letrero brillante, que diga, Casa de Vacunación Pública, no conviniendo de manera alguna el que á los principios se haga depósito de este precioso preservativo de los Hospitales, Hospicios, y Casas de Expósitos».

La casa destinada a la vacunación y a albergar la Junta de Vacuna debe «estar situada en el centro de la Ciudad, y ser muy cómoda y decente, para que el público concurra sin el menor tedio a recivir el veneficio que se les dispensará gratuitamente» ${ }^{63}$. Con esta localización, se intenta separar el concepto de enfermedad del de vacunación para evitar el rechazo de la población hacia la medida profiláctica. Por ello, en muchas ocasiones las Juntas de Vacunación se vinculan a las parroquias, ya que allí es donde están los únicos libros de registro de nacimientos que hay hasta 1869 , que son los Libros de Bautismos.

Las Juntas de Vacunación se establecen en función a tres criterios que condicionan la organización de las mismas y el desarrollo de sus competencias. Primero, determinan el modo de distribución de la vacuna y los medios humanos y económicos que se emplearán para distribuirla por los diferentes territorios. Segundo, realizan las vacunaciones, y eligen y forman a los vacunadores. $\mathrm{Y}$, tercero, se establecen en los puntos geográficos que poseen el fluido vacuno y lo distribuyen a los que carecen de él.

63 Artículos de la Instrucción para el establecimiento de la Casa de Vacunación Pública en la ciudad de México. Elaborados por el Conde de la Cadena, fechados en Puebla de los Ángeles el 27 de octubre de 1804. AGI: IG, 1558-A. 
La organización de las Juntas de Vacuna conformaba una red interrelacionada y compleja. En la Corte tenía su sede la Junta Suprema de Sanidad. De ella dependían las Juntas Centrales, que residían en las capitales de provincia en España y en las capitales de la Real Audiencia en América. De las Juntas Centrales dependían las llamadas Juntas Subalternas que se establecían en las ciudades más pobladas de los territorios.

La Junta Central de Vacuna se creó por Real Orden el 21 de abril de 1805.

«Estas Reales Juntas Filantrópicas españolas de vacunación, no serán otra cosa que unas corporaciones compuestas de las primeras autoridades militares, civiles y eclesiásticas, en unión de los vecinos que voluntariamente quieran subscribirse, con la precisa obligación de ser individuos natos de ellas, los señores curas párrocos y los profesores de Medicina y Cirugía» ${ }^{64}$.

Esta institución fue erigida para establecer relaciones con los territorios americanos. Si tomamos como referencia el «Reglamento para perpetuar en las Indias la Vacuna, del establecimiento de una Junta Central y Casa de Vacunación pública», podemos afirmar lo siguiente. La Junta de Vacuna estaba compuesta por dos «Protectores», uno secular, que coincidía con el Gobernador o Capitán General, y otro eclesiástico, que correspondía con el Obispo «en donde lo hubiere». A estos protectores hay que añadir ocho «Socios», «tanto eclesiasticos como seculares que mas muestras hayan dado de su zelo patriótico, y serán individuos natos de ella» (artículo $1^{\circ}$ ). Se recomienda que formen parte de este grupo el Alcalde y el Síndico Procurador General. De la totalidad de los socios se elegirá «el mas idoneo para las funciones de secretario de ella por lo tocante á lo gubernativo y correspondencia con los pueblos de la Provincia» (artículo $2^{\circ}$ ). De los asuntos médicos se ocuparán dos facultativos; de ellos uno se elegirá con funciones de secretario para que se encargue de los asuntos científicos. Ambos facultativos darán parte de las variaciones y las evoluciones que ocurran en los vacunados y levantarán acta de las sesiones que celebre la Junta Central ${ }^{65}$.

Las Juntas dependían del poder civil y eclesiástico y estaban integradas por autoridades que hubiesen mostrado un interés especial por el bienestar público. De este grupo debían salir el presidente, que era un cargo honorífico, y el secretario, que debía controlar el correo con las distintas provincias, y se

64 GonzÁlez, F. (1814), Discurso médico-politico sobre el Estado de abandono en que se halla la práctica de la vacuna, y los medios que pudiéramos emplear en España para hacerla permanente, hasta la extinción del contagio de la viruela, Imp. de Sancha, Madrid, p. 83.

$65 C f$. RAMíREZ MARTín (1999), p. 432. 
recomendaba que un facultativo controlase la calidad de las vacunaciones. Estas debían ser gratuitas. Había que revisar a los vacunados una semana después para aprovechar su linfa para nuevas vacunaciones, ofreciendo en ocasiones a los más pobres una pequeña gratificación económica por ello.

\section{JUNTA CENTRAL DE VACUNA}

Organigrama de los miembros

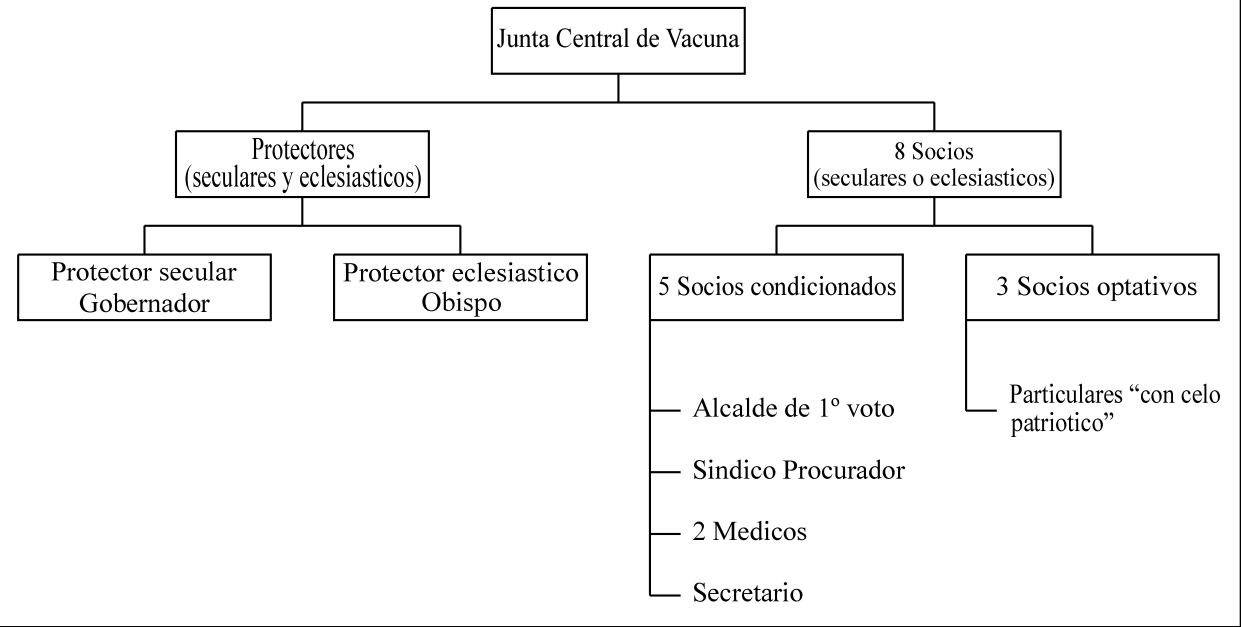

Los miembros de las Juntas de Vacuna no tenían salario asignado, puesto que se consideraba que estaban colaborando en una tarea filantrópica y humanitaria $\left(\right.$ artículo $3^{\circ}$ ). Esta era la causa por la que se recomendaba que se renovase cada año la mitad de los miembros para que no se perdiese el entusiasmo, no se agotasen los ánimos y no se quemasen las inquietudes. Pero la realidad es que recibieron sueldo algunos miembros que eran considerados esenciales en el organigrama de la Junta de Vacuna, como los médicos (artículo $3^{\circ}$ ).

Las Juntas Subalternas de Vacuna son creadas «con el fin de evitar que por algun descuido ú omisión llegue á perderse [el fluido] en la Capital» (artículo $8^{\circ}$ ). El motivo generador de estas Juntas es la generalización de la vacuna a todos los territorios dentro de una región geográfica. 
Estas Juntas se establecerán en todas las «cabezas de partido» (artículo $8^{\circ}$ ), siempre bajo la protección y el control de la Junta Central y «el distrito de cada Junta abrazará los pueblos mayores y menores, que según la división civil se hayan agregado al Ayuntamiento respectivo». Estarán compuestas por «el Cura Párroco, el Subdelegado» (era al mismo tiempo teniente Justicia Mayor) «el Administrador de Rentas» (era miembro de la Real Hacienda), «el Profesor de Medicina ó Cirugía que hubiere, y los vecinos mas distinguidos, con el Gobernador de Yndios» (artículo $8^{\circ}$ ).

La autoridad máxima de las Juntas Subalternas no es otra que la de los Justicias Mayores que las presiden. Estos «no ejerceran ninguna autoridad directa ni indirecta sobre los tenientazgos anexos, ciñéndose en sus correspondencias al tono de aviso, advertencia u amonestación, y limitando sus funciones a la conservación del fluido vacuno a su distribución, a poner en noticia de este cuerpo cuanto consideren conveniente sobre ambos objetos, y a ser únicamente el conducto por donde se trasmitan las disposiciones de la Junta Central, y por donde pasen a ella las listas o estados periódicos» ${ }^{66}$.

A esta directiva de las Juntas Subalternas se añadirán cuatro o seis vocales que se nombrarán «de los primeros sujetos del vecindario, prerfiriendo a los que se distingan no solo por su esfera, sino por su patriotismo y conocimientos». Estos vocales servirán de fermento para la propagación entre sus conciudadanos. Serán los difusores de la vacuna entre sus iguales. Además de los vocales, la Junta tendrá un Secretario «para extender los acuerdos con un cuaderno foliado, autorizarlos y llevar el despacho; pero donde no hubiere persona que pueda o quiera encargarse de tan delicada misión, lo hará por sí mismo el teniente Justicia Mayor ${ }^{67}$.

Todos los miembros de la Junta deberán influir para favorecer la propagación de la vacuna, y a ejemplo de la Junta Central deberán guardar en sus deliberaciones el concierto y unanimidad, sin los cuales las mejores Instituciones se hacen viciosas, y la distribución de los bienes que interesan a la sociedad se obstruye y paraliza.

Estas Juntas deben ser un fiel reflejo de las Juntas Centrales y a éstas rendirán cuentas (artículo $8^{\circ}$ ). Las sesiones de las Juntas se celebrarán «una vez a

$66 \mathrm{~N}^{\mathrm{o}} 2$, Artículo $3^{\circ}$ del Reglamento que puede servir a la creación, forma y primeras funciones de la Junta Subalterna de Vacuna, fechado en Caracas el 12 de diciembre de 1807. En Grases, P. (1979), Dos textos de Andrés Bello en la Junta Central de Vacuna, Caracas, 1807-1808, Ed. La Casa de Andrés Bello, Caracas, pp. 17-21.

$67 \quad \mathrm{~N}^{\mathrm{o}} 3$ y 4 , Artículo $1^{\mathrm{o}}$ del Reglamento. En GRASES (1979), pp. 17-21. 
la semana en la casa del teniente Justicia Mayor, o en la que de común acuerdo se tenga a bien» ${ }^{68}$.

El primer objetivo y responsabilidad de la Junta Subalterna es proporcionar en las poblaciones de su control la presencia del fluido, a cuyo fin tratará de que se forme una expedición con el menor costo posible para transportarle del paraje más cercano, y esta manera de propagar la vacuna es en forma dendrítica.

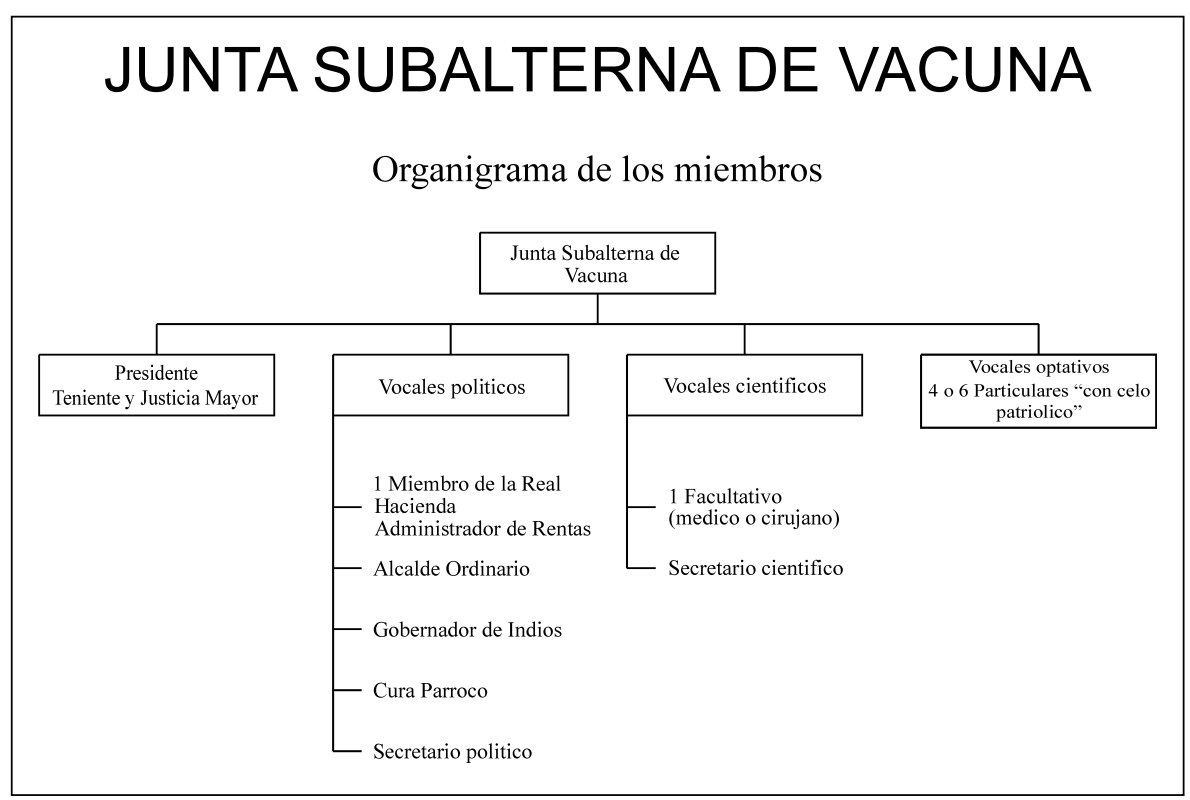

A las Juntas Subalternas llegará el fluido vacuno siempre que se necesite: «se efectuará por medio de un niño vacunado, que embiaran al efecto á la Capital, acompañado del Facultativo del pueblo, si pudiese ser, a fin de que presenciando la vacunación publica de la Capital, se instruya de algunos por menores de esta nueva practica» (artículo $10^{\circ}$ ), «cuyo conocimiento le franquearán los vacunadores comisionados, para evitar el riesgo de las falsas vacunas (artículo $9^{\circ}$ ). Este hecho funda la esperanza de que estos establecimientos sean los más utiles á la felicidad del estado y salud pública (artículo $10^{\circ}$ ). Estas expediciones regionales se financiarán por medio de una «suscripción

$68 \mathrm{~N}^{\mathrm{o}}$ 7, Artículo $1^{\circ}$ del Reglamento... En GraSES (1979), pp. 17-21. 
del vecindario o mediante otros arbitrios que la Junta considera preferibles, y que anticipadamente pondrán en noticia de la Central» ${ }^{69}$.

La Junta Subalterna tendrá como misión preocuparse por dos importantes aspectos. Uno, meditar de antemano los medios de conservar el fluido vacuno bajo su custodia y responsabilidad, aunque lo que se recomienda es que se practiquen «vacunaciones públicas de nueve en nueve días, por un operario que reuna los conocimientos y destrezas posibles $\gg{ }^{70}$. Y otro, proveer los medios «para conseguir que ocurran a vacunarse todas las personas que lo necesiten, para poder establecer una oportuna y activa circulación del fluido en los pueblos circunvecinos, teniendo a la mira su población y sus recursos» $\rangle^{71}$. El objetivo es que haya una proporción entre el número de nacidos y el de vacunados. La única condición que se pone a las Juntas Subalternas es que todas las medidas que se tomen para realizar la misión cuenten con la consulta previa a la Junta Central ${ }^{72}$.

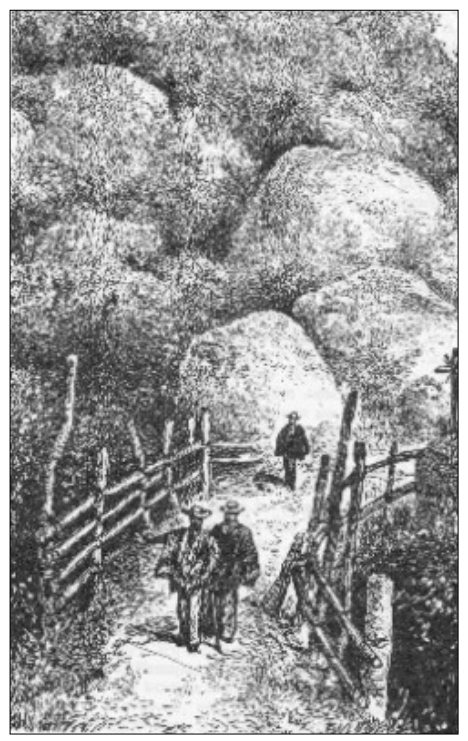

Viajeros en icononzo.

$69 \quad \mathrm{~N}^{\mathrm{o}} 3$, Artículo $2^{\circ}$ del Reglamento... En GraSES (1979), pp. 17-21.

$70 \quad \mathrm{~N}^{\mathrm{o}} 4$, Artículo $2^{\circ}$ del Reglamento... En GraSES (1979), pp. 17-21.

$71 \mathrm{~N}^{\mathrm{o}} 5$, Artículo $2^{\circ}$ del Reglamento... En GRASES (1979), pp. 17-21.

72 «Tratará sobre cuanto crea conducente a realizar las intenciones del Soberano, proponiéndolo todo a la Junta Central». No 5, Artículo 2º del Reglamento... En GRASES (1979), pp. 17-21. 